\title{
Patterns of Inequalities in Digital Agriculture: A Systematic Literature Review
}

\author{
Sarah Hackfort $\mathbb{D}$
}

check for

updates

Citation: Hackfort, S. Patterns of Inequalities in Digital Agriculture: A Systematic Literature Review. Sustainability 2021, 13, 12345. https://doi.org/10.3390/su132212345

Academic Editor: Dalia Štreimikienè

Received: 29 September 2021

Accepted: 5 November 2021

Published: 9 November 2021

Publisher's Note: MDPI stays neutral with regard to jurisdictional claims in published maps and institutional affiliations.

Copyright: (C) 2021 by the author. Licensee MDPI, Basel, Switzerland. This article is an open access article distributed under the terms and conditions of the Creative Commons Attribution (CC BY) license (https:/ / creativecommons.org/licenses/by/ $4.0 /)$.
Agricultural and Food Policy Group, Humboldt-Universität zu Berlin, Unter den Linden 6, 10999 Berlin, Germany; sarah.hackfort@hu-berlin.de

\begin{abstract}
Digitalization of agriculture is often hailed as the next agricultural revolution. However, little is yet known about its social impacts and power effects. This review addresses this research gap by analyzing patterns of inequality linked to the development and adoption of digital technologies in agriculture and reviewing the strategies developed to reduce these inequalities and challenge the power relations in which they are embedded. Analysis of 84 publications found through a systematic literature review identified five patterns of inequality: (1) in digital technology development; (2) in the distribution of benefits from the use of digital technologies; (3) in sovereignty over data, hardware and digital infrastructure; (4) in skills and knowledge ('digital literacy'); and (5) in problem definition and problem-solving capacities. This review also highlights the existence of emancipatory initiatives that are applying digital technologies to challenge existing inequalities and to advance alternative visions of agriculture. These initiatives underscore the political nature of digital agriculture; however, their reach is still quite limited. This is partly due to the fact that existing inequalities are structural and represent expressions of corporate power. From such a perspective, digitalization in agriculture is not a 'revolution' per se; rather, digital technologies mirror and reproduce existing power relations.
\end{abstract}

Keywords: digital agriculture; inequalities; power; data sovereignty; political economy; systematic literature review

\section{Introduction and Rationale for the Review}

'Smart farming', 'agriculture 4.0' and 'digital agriculture' are largely interchangeable terms used to describe the phenomenon of increased use of data-related technologies in the farming and food production process. These technologies make use of big data, artificial intelligence, and automation along the entire commodity chain, from input production to crop production and harvesting, packaging, transportation and consumption. At the input level, they include digitally enabled genome editing and biofortification, as well as microfinance programs and insurance systems. On the farm, smart machinery is used for crop production and harvesting. Sensors are used to monitor soil moisture and plant nutrition requirements, and to detect the presence of pests and diseases. Decision support apps help farmers to apply fertilizers and pesticides when and where they are needed. Remote satellite imagery is utilized to monitor biomass growth, complemented by pictures and data collected from drones and robots scanning the fields. Farm management software is used by farmers to prepare the documentation required to comply with regulations, obtain subsidies, and market their products. Much of the agricultural data generated by these digital technologies is stored on data platforms and in clouds hosted by technology and service providers [1-4]. 'Digital agriculture' encompasses both digitization, which refers to the technical process of converting analogue information into digital data, and digitalization, understood as the social process of adoption of computer technologies [5]. The ever-greater penetration of these technologies into social and economic life brings about a digital transformation, including in agriculture, where digital technologies are contributing to a reshaping of production processes across the globe. The digitalization of agriculture is widely hailed as the next agricultural revolution [6]. However, while 
numerous case studies analyze specific instances of digitalization, aggregated data is scarce and little progress has been made towards a systematic overview of the adoption of different types of digital agriculture on a global scale [1]. Even less is known about the social impacts and power effects of the digitalization of agriculture. As portrayed by policies and industry, digital agriculture benefits the environment and farmers by increasing productivity. Corporate leaders and policy institutions argue that digitalization offers the solution to feeding a growing world population, while at the same time mitigating the negative environmental and climate consequences of industrial agriculture (see $[7,8]$ ). This picture is an affirmative and positive one, generally conflict-free and with few if any downsides. In contrast, some civil society organizations adopt a more critical attitude, drawing attention to problematic impacts on, for example, labor relations and social justice. These organizations see digitalization as a threat to food sovereignty and the livelihoods of smallholders [9]. The academic literature presents a more nuanced picture. Studies highlight the social and economic opportunities, while acknowledging that digitalization also entails challenges and risks [10-12].

For example, Regan et al. [13] report that farmers perceive both the benefits of digitalization and the risks it entails, including loss of knowledge, devaluation of their profession, and potential misuse of data. In this context, and given the pace of the development of digitalization in agriculture, the question of who gains and who loses from its adoption should receive particular attention. However, only few studies have examined the social impacts and distributive dimensions linked to the adoption of digital technologies in agriculture (see for example [14-17]). Klerx et al. [16] review the recent social science literature on digital agriculture, focusing on power, ownership, and ethical issues, and make suggestions for a future research agenda. Rotz et al. [17] diagnose key challenges and tensions in the field from a social justice perspective, highlighting issues relating to the ownership and control of data, production technology, and data security. They also point to the need for more research on the impacts of digitalization on agricultural labor, and how these impacts affect vulnerable social groups in the agrifood sector. Some of these contributions highlight the unequal distribution of the benefits of digitalization in agriculture. Several studies of digital agriculture within the field of responsible research and innovation emphasize the importance of equity and inclusiveness in digital innovation, and have developed frameworks to analyze and facilitate the inclusion of farmers in innovation processes [14,15,18-24].

These insights are acknowledged in this review; however, the aim is to go a step further. Simply calling for more inclusion and developing tools to this end fails to address the underlying structural reasons why farmers are often excluded from innovation processes. Elucidation of these structural constraints on inclusion requires an analysis of the social inequalities affecting the individual and collective access to goods, resources, and employment across multiple and sometimes overlapping axes, including race, ethnicity, class, gender and age. Against this background, this review addresses the following research questions:

- What patterns of inequality are linked to the development and adoption of digital technologies in agriculture?

- What strategies to reduce inequality are being developed in the field?

Inequalities influence the scope of action of social actors through unequal distribution of risks and benefits, of access to resources and control over their allocation and use, and through knowledge asymmetries. This conceptualization of inequality and the interest in strategies of contestation draws on the work of political ecologists addressing unequal power relations in the context of society-nature relations and, in particular, on studies focusing on strategies of resistance that challenge existing power relations and inequalities $[25,26]$. Empirical studies in this field have identified patterns of social-ecological inequality in relation to different environmental issues (e.g., resource extraction), while theoretical studies have mapped them out conceptually. Socio-ecological inequalities identified relate to: (a) the (re)distribution of environmental risks, costs and benefits: (b) access to 
natural resources; (c) the capacity to cope with changing environmental conditions; (d) responsibility for socio-ecological crises. and (e) asymmetries in power relations which shape the production of knowledge, problem definitions, and the search for solutions (for an overview, see [27-29]). Studies of food justice, food sovereignty, and food regimes analyze and conceptualize food-related inequalities, while many of these focus on gender-related and intersectional inequalities and the efforts of social movements to challenge existing power relations [30-32]. Food regime theory, as developed chiefly by [33,34], pays special attention to power effects and class inequalities arising from the "corporate-environmental food regime" [34]. Critical agrarian studies address technology-related asymmetries in agriculture and study the unequal effects of technological innovation [35,36]. Many of these studies focus on the emergence of inequalities among countries and farmers as a result of the adoption of agricultural biotechnology during the green revolution, considered as the dawn of a neoliberal restructuring of agriculture [37] which led to a dramatic increase in corporate power over food production [38].

However, only a few studies to date in the fields of political economy and ecology and critical agrarian studies have specifically addressed the role of digitalization in agriculture. The analysis of inequalities linked to digital technologies in agriculture and the development of strategies to challenge the power relations in which they are embedded is a significant research gap. This review starts from the premise that bringing together these two research traditions can help to unpack these issues and lead to a better understanding of how digital technologies impact social inequalities in the agricultural and food systems. This, in turn, is the starting point for identifying feasible pathways to change through political action, both by social movements and policy makers.

This paper presents the results of a systematic literature review of the academic literature relating to patterns of inequalities in digital agriculture. The next section describes the methodology adopted for data sampling and analysis. It is followed by the presentation of results which describe the principal patterns of inequalities and resistance strategies identified in the literature review. The discussion of results, which includes suggestions for further research, is followed by brief conclusion.

\section{Methodology}

The methodology adopted herein is based on standard systematic review procedures (such as the PRISMA statement) incorporating a search strategy, extraction of records, and reporting of results $[39,40]$. Such a review is appropriate as a research method when the goal is to provide an overview of research in different fields on a specific topic and to discuss research developments or compare research on the topic across disciplines. It can also be used to explore themes, theoretical perspectives, or specific issues within a field of research or discipline in order to identify elements of a concept or of a novel approach [39]. Deductive content analysis was employed to analyze the retrieved material in order to identify patterns of inequality revealed in the literature.

Scopus was used as the database. This is one of the largest databases of abstracts and citations, and is widely recognized as a trustworthy database for academic research [41]. It was selected because of its comprehensive coverage of international and regional academic journals, as well as the availability of metadata and the accessibility and ease of extraction of data compared to other databases (e.g., Google Scholar). Scopus was searched using the following key search terms:

(TITLE-ABS-KEY ("digital agriculture") OR TITLE-ABS-KEY ("precision technologies") OR TITLE-ABS-KEY (“digital farming”) OR TITLE-ABS-KEY (“agriculture 4.0”) OR TITLE-ABS-KEY ("precision agriculture")) AND "conflict" OR "social relations" OR "power" OR "inequality" OR "governance" AND (LIMIT-TO (SRCTYPE, "j")) AND (LIMITTO (SUBJAREA, “AGRI") OR LIMIT-TO (SUBJAREA, “SOCI”)) AND (LIMIT-TO (DOCTYPE, “ar")) AND (LIMIT-TO (LANGUAGE, "English”)).

In addition to the key term 'inequality', other search terms were chosen in order to identify articles related to the specific focus of the review (e.g., power, conflict, social 
relations). The search was not geographically restricted, and covered all relevant journal articles published in English ("English") at any time until the date of retrieval. These included research papers and review papers (strings " $j$ " and "ar") in the fields of social and agricultural sciences (strings "agri" and "soci"), while excluding conference reports and papers and purely technical contributions from data or engineering sciences. A total of 340 results were retrieved on 28 January 2021. In a second step, the sample was narrowed down to include only documents dealing with social relations and governance issues in relation to the development and use of digital technology in agriculture. To this end, all abstracts were checked for eligibility, and articles that did not address these issues were excluded. Excluded articles included those focusing solely on the development or adoption of a specific agricultural technology or model. This refinement reduced the number of articles for consideration in the review to 51. To update this sample, a second retrieval was performed on 11 August 2021. This resulted in 400 hits, from which 21 further articles were added to the sample after the eligibility check. Finally, another 12 items were added to the sample (including one conference paper and one technical report by the European Commission), identified through a snowball search (i.e., recommendations from colleagues and reviewers, see Figure 1). Excel was used to compile the data and perform the eligibility assessment, using the inclusion and exclusion criteria to narrow the selection down to relevant publications. The final sample of 84 was subjected to in-depth qualitative analysis using deductive coding, with categories derived from the research focus on inequalities. The analysis considered: (a) the regional context of the case studies reported in the articles; (b) the types of technology and their application; (c) dimensions of inequality, including asymmetries, conflicts, and other distributive issues relating to access to, control over, and ownership of digital technology and/or data; and (d) impacts on skills, knowledge, and problem definition and problem-solving capacities. The analysis also identified (e) initiatives to address these inequalities and their impacts, and the actors involved.

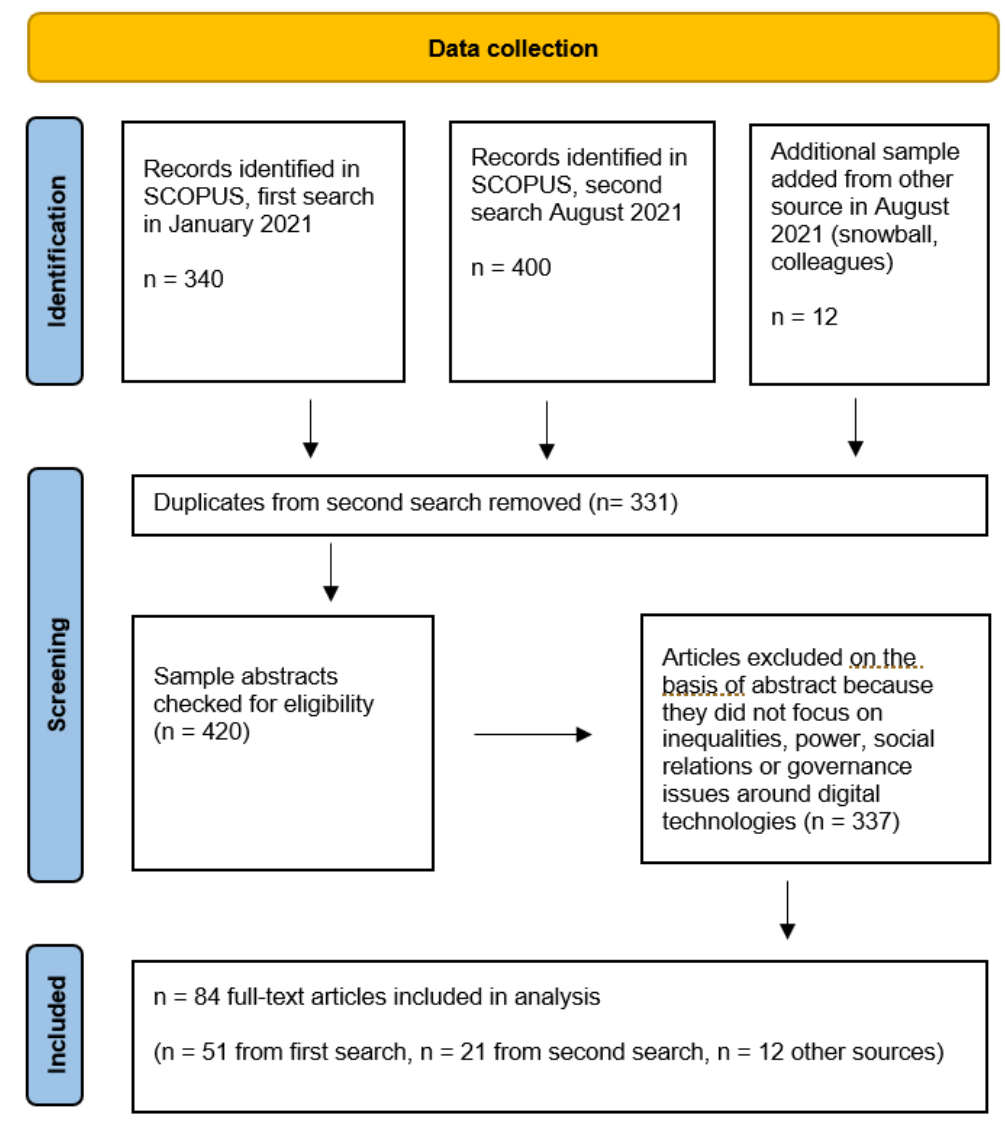

Figure 1. PRISMA-based methodology used for data collection. 


\section{Results}

Descriptive analysis of the data showed that digital agriculture is a new research topic that has received considerably increased attention over the past 10 years. Of the 84 articles, one was published in 2004, four in 2017, 12 in 2018, 17 in 2019, 21 in 2020, and 21 in the eight months leading up to August 2021 (see Figure 2). This growth in the number of published articles indicates the increasing importance of the topic and its relevance in academic discourse.

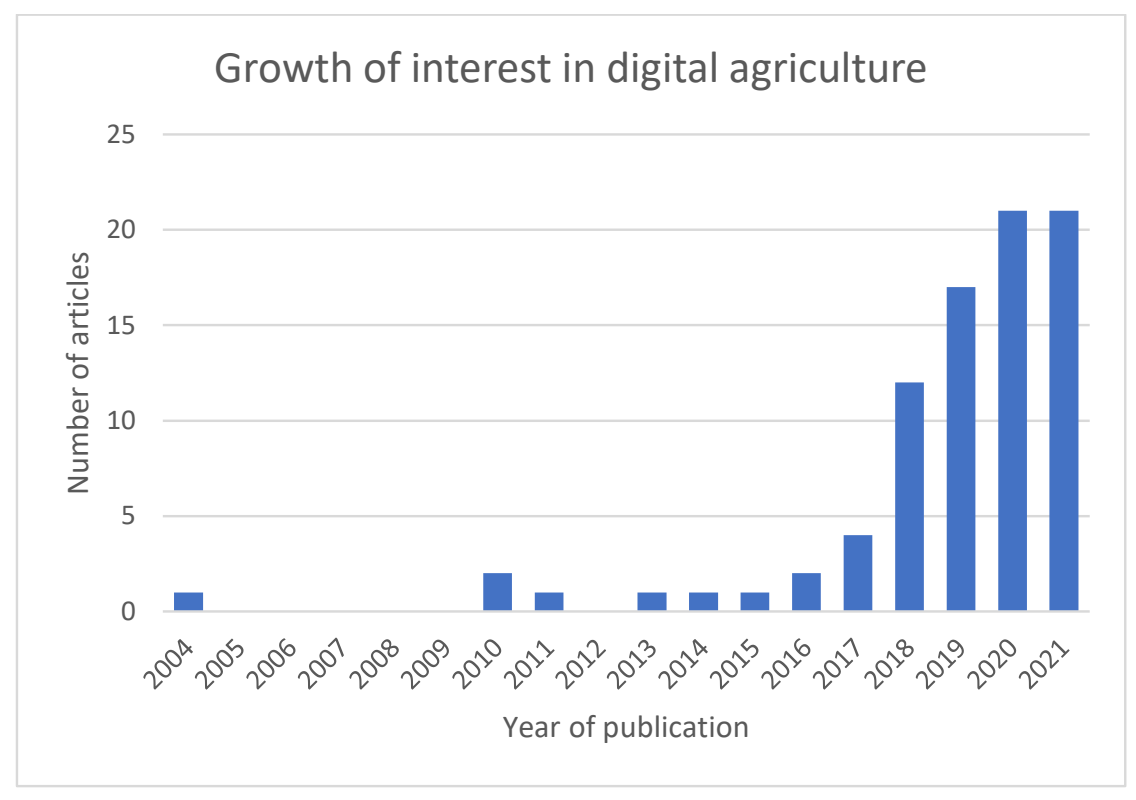

Figure 2. Year of publication of articles analyzed in the review, based on a literature search that identified articles published up to August 2021.

There is a significant regional bias in the analyzed literature towards the more industrialized countries (Figure 3). Among country studies, fifteen focus on the USA, eight on Australia, and seven on Canada. In addition, there are ten regional studies of Europe and five of North America. In contrast, only six articles explicitly cover developments on the African continent, including three regional studies and three country studies (two of Ghana and one of Nigeria). Given this bias towards North America and Europe in the literature, it is inevitable that the findings presented in this review mainly reflect developments and inequalities in these industrialized countries. However, this bias in the literature does not necessarily mean that digitalization in agriculture is not affecting other regions. It might reflect the fact that the development of inequality in digital agriculture in the Global South is not yet a focus of academic research and needs to be further explored. The preponderance of studies of the Global North, and North America in particular, could also be the result of biases in the compilation of the SCOPUS database, leading to underrepresentation of journals and authors from other parts of the world. This is also suggested by the composition of the sample initially retrieved from Scopus (before limiting the search to English articles), which contained only two articles in Chinese, and one in each of German, Portuguese, and Spanish.

The qualitative analysis identified five main patterns of inequalities (see Table 1 below), relating to: (1) control of technology development; (2) distribution of the benefits of technologies; (3) sovereignty over data and hardware; (4) knowledge and skills; and (5) capacity to define and solve problems. These are described in the following sections, with examples from the analyzed literature. Each section includes a review of the different strategies that are being developed by actors in the field to challenge the pattern of inequality in question. 
Table 1. Patterns of Inequality in Digital Agriculture.

\begin{tabular}{|c|c|c|c|c|}
\hline \multicolumn{5}{|c|}{ Patterns of Inequality in Digital Agriculture } \\
\hline $\begin{array}{l}\text { Inequalities in Control over } \\
\text { Technology Development }\end{array}$ & $\begin{array}{l}\text { Unequal Distribution of Benefits } \\
\text { from Technologies }\end{array}$ & $\begin{array}{l}\text { Uneven Sovereignty over Data } \\
\text { and Hardware }\end{array}$ & $\begin{array}{l}\text { Inequalities in Knowledge } \\
\text { and Skills }\end{array}$ & $\begin{array}{l}\text { Unequal Problem Definition and } \\
\text { Problem-Solving Capacities }\end{array}$ \\
\hline $\begin{array}{c}\text { Multinationals } \\
\text { produce agricultural inputs (Syngenta, } \\
\text { Bayer AG) and machinery (John } \\
\text { Deere, BOSCH), and technology } \\
\text { companies (IBM, SAP) control } \\
\text { technology development }\end{array}$ & $\begin{array}{l}\text { Innovation is mainly directed } \\
\text { towards capital-intensive solutions } \\
\text { benefiting large-scale farms }\end{array}$ & $\begin{array}{l}\text { Data storage is controlled by } \\
\text { technology providers (e.g., Bayer } \\
\text { AG's Climate Corporation) }\end{array}$ & $\begin{array}{l}\text { Unequal digital literacy: even if } \\
\text { farmers are given access to data, } \\
\text { they lack the software and skills } \\
\text { used by corporate actors to extract } \\
\text { value from the data }\end{array}$ & $\begin{array}{l}\text { Dominance and prioritization of } \\
\text { capital-intensive technology and } \\
\text { productivist solutions to structural } \\
\text { problems }\end{array}$ \\
\hline $\begin{array}{l}\text { Lack of interoperability of systems } \\
\text { and machines and incompatibility of } \\
\text { software solutions lead to dependence } \\
\text { of farmers and consumers on } \\
\text { providers }\end{array}$ & $\begin{array}{l}\text { Uneven access to digital } \\
\text { infrastructure deepens the } \\
\text { urban-rural divide among farmers }\end{array}$ & $\begin{array}{l}\text { Farmers are disadvantaged by } \\
\text { disparities in bargaining power, } \\
\text { since single-farm data is less } \\
\text { valuable than aggregated big data }\end{array}$ & $\begin{array}{c}\text { Farmers are increasingly } \\
\text { dependent on providers of big } \\
\text { data-generated knowledge and } \\
\text { maintenance services }\end{array}$ & $\begin{array}{c}\text { A productivist approach based on } \\
\text { digitalization is the dominant vision } \\
\text { of the future of agriculture in policy } \\
\text { discourses }\end{array}$ \\
\hline $\begin{array}{c}\text { Technical lock-ins limit farmers' } \\
\text { options and constrain their decision } \\
\text { making }\end{array}$ & $\begin{array}{l}\text { While farmers take huge financial } \\
\text { risks when investing, technology } \\
\text { providers benefit from the use of } \\
\text { data supplied free of charge by } \\
\text { farmers }\end{array}$ & $\begin{array}{l}\text { Private license agreements, } \\
\text { including legal lock-ins, deny } \\
\text { farmers access to their farm data; } \\
\text { sometimes even self-repair of } \\
\text { hardware is prohibited }\end{array}$ & $\begin{array}{l}\text { Opportunities to hire skilled } \\
\text { employees differ among farmers, } \\
\text { especially across the urban-rural } \\
\text { divide, disadvantaging farmers in } \\
\text { rural areas and those with fewer } \\
\text { financial resources }\end{array}$ & $\begin{array}{l}\text { The fixation on technological } \\
\text { solutions diverts attention and } \\
\text { material investments away from } \\
\text { other approaches, such as } \\
\text { agroecology and food sovereignty, } \\
\text { that define problems differently and } \\
\text { propose alternative solutions }\end{array}$ \\
\hline
\end{tabular}




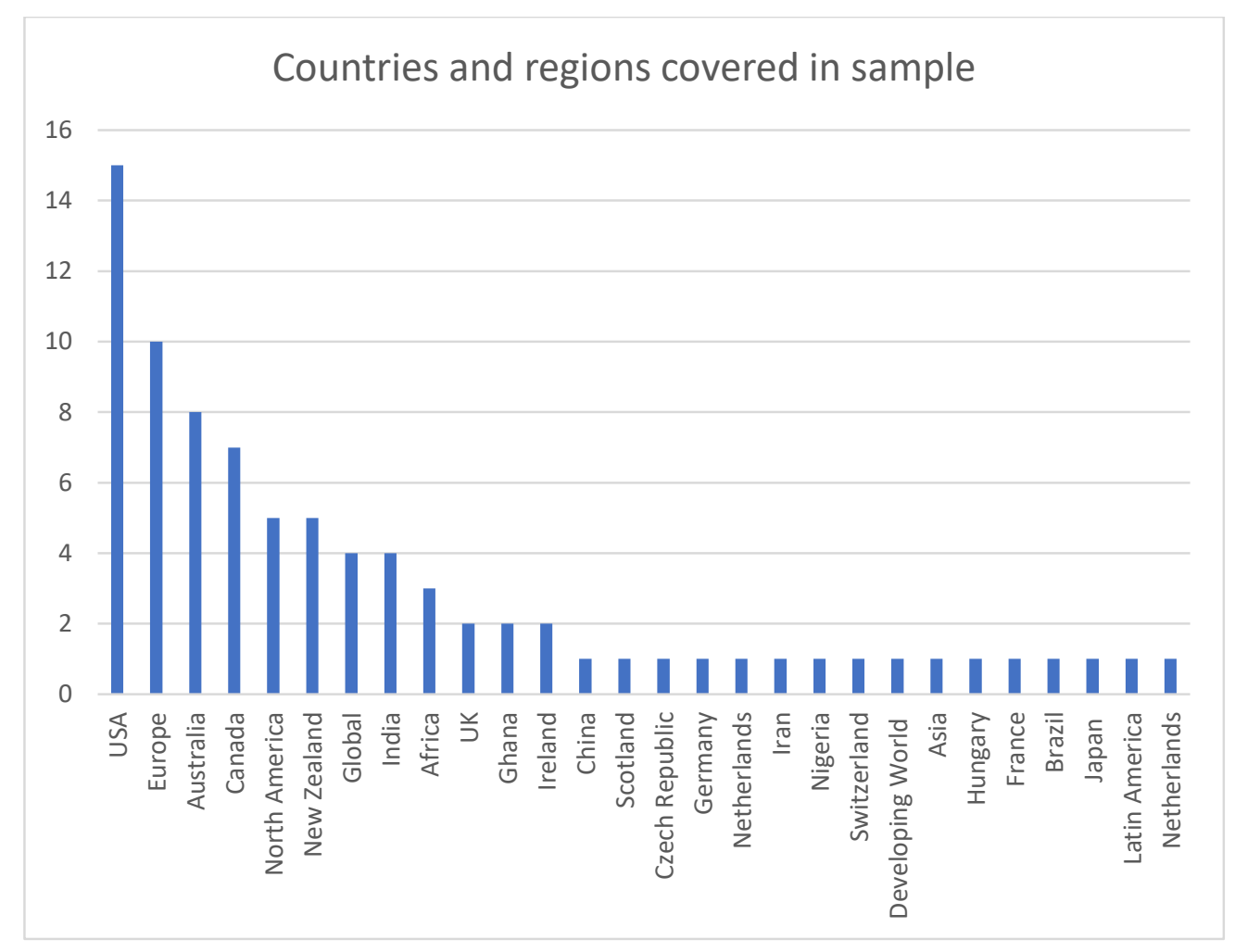

Figure 3. Frequency of countries and regions covered in the sample.

\subsection{Inequalities in Control over Technology Development}

The digital transformation of the food system is largely driven by private multinational firms. In [1], the authors identify four main groups of actors: (a) giant corporations producing agricultural inputs, such as Bayer Ag and SYNGENTA; (b) new agri-tech players from the software and big data sector, such as Alphabet, IBM, SAP, and Alibaba; (c) machinery and hardware companies, such as BOSCH and John Deere; and (d) private sector start-ups. The first two groups dominate technological innovation along the entire food commodity chain, driving the development of GMO seeds, farm management platforms, and automated warehouses [1,2]. Their economic power enables them to control the direction of technological development, including how it is used by farmers $[12,19]$. The leading role of agribusiness and tech firms in the development and commercialization of digital agriculture technologies consolidates economic concentration, increasing the dependency of farmers and consumers on these powerful actors as well as their control over agricultural production $[19,42]$. This could exacerbate the existing divide between large-scale and small-scale farms, leading to a situation where a small number of digitally equipped large-scale farms produce an ever-greater share of agricultural output [42]. Similar observations have been made with regard to the impact of Green Revolution technologies [24] in both developed [11,17,43,44] and developing countries [6].

Innovation generally occurs when investment capital is available and responds to the needs of the investors. Because of the scale of capital investment in agriculture and the pressure this creates to produce a return on investment, most agricultural innovation is undertaken by high-tech and capital-intensive companies and directed towards their needs. This effect is self-reinforcing and favors the concentration of digital technology in the hands of ever-fewer powerful actors [2,24].

New digitally-driven biotechnologies such as genome editing as well as the large number of digital farming start-ups that are proliferating across the globe raise some hope for the democratization of access and control, in particular through significantly decreased costs [12,45]. Novel technologies might create some potential for a more level 
playing field; however, large corporate actors still predominate through the concentration of technological know-how and infrastructure, ownership of data, ownership of patents on new genome editing technologies [2], and the imposition of legal or technical lockins that prevent independent use of new technology [46]. Moreover, many successful start-ups are quickly bought up by one of the big players, as in the widely-publicized case of the purchase of Climate Corporation's farming platform by Bayer AG (formerly Monsanto) for USD 930 million in 2013 [2,10,12]. One expression of this inequality in control over technological development is the lack of interoperability, which limits the ability of information technology systems to exchange data with each other and to make use of information held by other systems [17,47]. This imposes technical lock-ins, a barrier that prevents farmers from using technology systems from different service providers in accordance with their needs. Agricultural input and machinery companies impose similar lock-ins. They extract value from the data they collect on the use of digital technologies to lock farmers into their own product ecosystems (e.g., by targeted advertising of their own farm inputs or machinery). Some farm management platforms offer multi-tiered service packages, sometimes with a free basic version designed to attract a critical number of users and thus enhance market share. Through these mechanisms, farm management platforms, like other digital platforms, create legal and technical data lock-in mechanisms that restrict the freedom of their users [46]. This means that while the costs of using the platform may be low, switching to a different provider is often expensive or even impossible (e.g., due to the incompatibility of data formats) [2,12]. This lack of control over technology considerably limits autonomous decision making by farmers regarding their choice of software or hardware. Interoperable data production technologies and data management systems with transparent terms of use are essential if they are to become effective knowledge-enhancing and decision-making tools for farmers under their own sovereignty and ownership [48].

In response to this need, and despite the overarching dominance of large corporations, some alternatives have emerged. One example from Canada is the farmer-owned Three Rivers Farmers Alliance [49], whose members have developed their own smartphone app to help organize such farming activities as harvesting and processing. The app also connects them to local customers such as shops, schools or restaurants, who can use it to place orders for delivery [17]. Another example in the United States is Ag Hub (formerly Ag Xchange), an open and corporate-neutral farm data platform that enables farmers' control of data and promotes sharing among data users [50]. It is the result of cooperation between two non-profit initiatives, the farmer-owned Grower Information Services Cooperative and the Agricultural Data Coalition, an initiative by farmers, lawyers, business groups, and researchers. It claims to be the "industry's first cloud-based platform that will be controlled by growers and open to all industry service partners and technology providers" [43].

\subsection{Unequal Distribution of Benefits from Technologies}

The way digital technology is designed contributes to the unequal distribution of its benefits. Much of agricultural big data and much of the associated infrastructure is primarily designed to service farmers who follow a productivist strategy, which aims to maximize the output of commodity export crops; this is a model based around the intensification, industrialization and externalization of agriculture $[2,11]$. The exclusion of farmers who adopt a different approach contributes to increased inequality not only between farmers and agribusinesses but also among farmers themselves (e.g., small scale vs. large scale, conventional vs. organic) [11]. Adoption and use of digital farming technologies is already higher on large farms dedicated to the production of commodity crops, particularly in industrialized countries with a highly concentrated farm structure [12,51]. Here digitalization deepens the digital divide between larger, capital-intensive farms and those unable or unwilling to purchase digital technologies [11,24,44]. Their adoption might further speed up the growth of larger farm holdings at the expense of smaller ones, a phenomenon already evident in the United States and increasingly also in Europe [43]. 
Existing socio-economic and spatial asymmetries in digital infrastructure development contribute to unequal access to the internet and impact the ability of farmers to use digital technologies [8]. These include the growing urban-rural divide, whereby rural areas are at a disadvantage in this respect compared to urban ones in many parts of the world, in addition to other disparities among different groups of smallholder farmers, including gender inequality [52]. Such inequalities are reinforced by the pressure on farmers to comply with regulations (e.g., global food safety standards or requirements for receiving agricultural subsidies). These compel farmers to adopt digital technologies in order to remain in the supply chain and compete with other early adopters [43]. For individual farmers, the costs of digitalization are not recoverable and, in contrast to conventional farm machinery (e.g., tractors), there is only a small resale market for digital infrastructure. This is partly because items of digital farming equipment such as sensors or drones are often customized and cannot be adapted for other uses. In addition, hardware prices are falling, so farmers have little motivation to buy or sell second-hand. As a consultant study highlights, the price for an automotive LiDAR sensor for self-driving tractors declined by $90 \%$ between 2010 and 2017, from USD 75,000 to USD 7000 [53]. Farmers assume all the financial risks of investing in digital services and devices to compete on the market [43] while the technology providers benefit from data freely provided by farmers, which has high use value as an input for the further development of data-based services. While the farmers still own the fields, they cede control over their data to the service providers. Farmers then have to pay the same service providers to access digital information generated in part from their own farm data, which they fed into the system without receiving any remuneration $[44,46]$. Rotz et al. [44] consider that this "unpaid work under digital capitalism" turns farmers into "digital labourers" who, moreover, have to pay "rent" to access data they themselves have produced. Thus, the financial returns on investments in implementing and using digital platforms are unevenly distributed. They are received by input suppliers, or technology providers, who benefit from reduced transaction and product optimization costs, and only to a lesser extent by farmers themselves $[47,54]$.

\subsection{Uneven Sovereignty over Data and Hardware}

Digital agriculture increasingly depends on the extraction and analysis of large amounts of data. As stated in the previous section, agricultural data is often collected and stored using infrastructure manufactured, owned, and controlled by large companies providing digital technology, machinery, or other inputs to farmers [2]. Both access to this data and control over its use are very unequally distributed. Technology providers, in particular, enjoy "a privileged position with unique insights into what farmers are doing around the clock, on a field-by-field, crop-by-crop basis," over large areas of the world [19]. For example, by 2018, the Climate Corporation platform Climate Field View had more than 100,000 registered clients in the United States, Canada and Brazil, who together farmed about 120 million acres [2,10]. Some machinery manufacturers (such as John Deere or AGCO) place "legal and digital 'locks' on hardware and software packages" that they sell to farmers [55]. This prevents farmers from accessing the data which these companies collect from the fields and from fully using their products. Sometimes, the full extent of the data collected and the uses it is put to are hidden from farmers in accordance with privacy and access agreements that the companies require them to sign [11].

In most cases, by signing such user agreements, farmers making use of a digital platform hand over control of their data to the provider company. These agreements drawn up by the data aggregators not only authorize data collection, but also limit farmers' access to the data and place restrictions on its further use [44]. Theoretically, farmers own the data they generate. However, the aggregated data is property of the company that collects, processes, and stores it [56]. Thus, in reality, farmers usually do not have full control of the data they generate. The end-user license agreements drawn up by the companies give rise to an unequal relationship, authorizing a 'data grab' that has been described as a form of dispossession [43]. Many platforms do not disclose their back-end processes to customers, 
and withhold information about how customer data is used and for what purposes. This uneven sovereignty reflects and at the same time is partly a result of the differences in bargaining power of the parties involved. It shows the weaker position of the farmers, due to the fact that data about a single farm has less economic value than aggregated big data compiled by the technology providers [46].

Even in cases where farmers can access their own data, their data sovereignty often remains limited because they lack the tools and capacity to analyze it. Thus, farmers' growing reliance on farm data management platforms such as Climate Field View increases their dependency on the firms providing these services. Farmers are sometimes not even aware of the legal content of the terms and conditions they agree to [48]. Studies of the legal regulation of farm management platforms in the European Union and United States, and of the voluntary codes that service providers have signed up to, illustrate the legal complexity of relationships among agricultural data users and providers. They also show that ownership is almost exclusively governed by private license agreements, in some cases based on existing voluntary codes of conduct $[46,48,56]$. It remains unclear who actually produces the data and has the right to decide on its further use, "as farmers may be data originators in one relationship with their advisor but then the advisor becomes data originator when dealing with agribusinesses who provide digital services" [48]. This might be one reason why there is currently no effective policy regulation in place in the United States or in the European Union to protect and strengthen farmers' sovereignty over the data generated on their farms. In contrast, in the European Union, the existing and rather "outdated" legal framework actually "enhances the position of the agricultural technology providers and third-party aggregators" [56], thereby legitimizing the 'data grab' discussed in the previous section [43].

In addition to being dispossessed of "their" data, farmers are sometimes denied sovereignty over the machines and equipment that they purchase. Legal locks in form of license agreements prohibit farmers from repairing their smart tractors themselves, and compel them to use only approved service providers. This is a consequence of legislation originally intended to prevent digital piracy, but that now makes it illegal for farmers to fix tractor engines or any other part of the equipment that is digitally controlled [17,52,57].

These inequalities have provoked some grassroots resistance. In the United States, farmers organizations are demanding the right to own their data and to repair their own farm equipment [15]. The US-based Right-to-Repair movement advocates for repairfriendly legislation backed up by standards and regulations (e.g., to guarantee purchasers the right to access information about products that they own, including the right to unlock software) [58]. The movement supports farmers' demands for the legal right fix their own farm equipment [12,52].

Farm Hack [59] is another initiative that links up farmers across the globe via an online platform where they can share experiences of assembling and repairing the hardware and software used on their farms $[12,60]$. Farm Hack collectives directly challenge inequalities in proprietary technology regimes in agriculture [42]. FarmOS is a tool developed by the Farm Hack community that is intended to overcome "technological inequities by introducing greater diversity into the digital agricultural socio-technical system" [19]. The free and open platform was developed in close cooperation with farmers, and can be hosted, installed and further developed by anyone who has the capacity (e.g., coding skills) to do so $[19,60]$. It enables farmers to stay at least partially independent of large corporations and to regain or maintain sovereignty over how their data is shared $[2,10,19,43]$. FarmOS and similar initiatives such as the OpenAg Data Alliance, Joindata, FarmLogs, and DJustConnect collect and use data "for and by farm owners without ag-input company ownership" and under their own sovereignty [61]. These initiatives provide alternative, low-cost open-source software on shared platforms that acknowledge farmers' ownership of their data and operate outside of corporate control $[10,17,43]$. 


\subsection{Inequalities in Technology-Related Knowledge and Skills}

Increasing digitalization requires skills that are not accessible to all [62]. Even if agricultural data were completely 'open-source' and under farmers' legal sovereignty, not all farmers possess the knowledge and skills required to process and analyze the data, or to correctly interpret the results [47]. The adoption of digital technologies requires farmers to invest time and money in learning new skills in order to gain a basic understanding of information technology systems and of how to interpret data outputs (e.g., for the identification of in-field management zones, which requires longitudinal data collection) [63]. As farmers become even more reliant on the use of digital technologies to guide their farming practices, lock-ins become self-reinforcing. Without help to develop the requisite knowledge and skills, they lose the ability to make decisions independently, or to repair their own digital equipment and machinery $[12,44]$. This new knowledge is needed to understand and analyze digital data. Few farmers have the financial resources to employ or hire employees with digital skills, which in any case may be hard to find in rural areas. Those that can hire such employees gain a competitive advantage over other farmers; thus, digitalization is likely to exacerbate existing inequalities (e.g., between small and large farms) [63]. Some studies portray this as a further manifestation of the urban-rural divide, whereby farmers in remote rural areas find it more difficult to access the skills needed to participate in digitalized agriculture than those based close to urban areas [8,64].

The increasing reliance on technical experts and technology may result in a loss of tacit knowledge if the cognitive processing of information is delegated to machines or algorithms [65]. Some fear that farmers will become even more dependent on the software and platform providers as they lose the ability to "read" their plants and animals without them [66]. On the other hand, delegation of some operational and basic activities to may leave farmers more time for "higher level" learning processes [65]. Digitalization may entail a readjustment of labor allocation on farms [67], possibly involving a reduction in the human labor force [52]. It is still unclear to what extent farmers' knowledge and human labor will be replaced by algorithms and automatons, or complemented by them. There is not much evidence of deskilling of farmers or farm laborers due to digitalization thus far [68]; however, studies find that "digital tools are used to increase surveillance and control" of the labor process on the farm, making it more transparent for employers. Increased surveillance and control over the workforce could possibly limit the will and ability of farm workers to collectively organize. This would further deepen the existing class inequality between labor and capital, in particular in the case of poorly unionized areas and for seasonal or migrant workers [68].

\subsection{Unequal Definition and Problem-Solving Capacities}

The capacity to define and shape the future of agriculture is unequally distributed among actors. The productivist industrial agricultural model is often presented by its proponents as key to achieving food security. However, it is criticized by movements for food sovereignty and small-holder farmers' alliances, among others, who call for a structural transformation toward agroecology or community-based organic farming. Several scholars argue that the digitalization of agriculture is highly entrenched in productivist farming systems and exacerbates their negative environmental effects, while increasing the concentration of corporate power over the food system through multiple lock-in effects and path dependencies $[2,11,12,57,69,70]$. The economic power of corporate agribusiness actors allows them to shape public discourse, whereby the environmental benefits of digital technologies are highlighted and the externalities often ignored [2,12].

These divergent visions of sustainable agriculture are linked to different assessments of the power of technology alone to solve sustainability problems, and regarding the social and ecological benefits and risks of digital precision technologies such as genome editing. The emphasis in the policies of high-tech agribusiness solutions on structural food system challenges demonstrates the power of corporate actors to define problems and their solutions. This makes it hard for alternative ideas such as those of the food 
sovereignty movement, which identifies agro-industrial structures as the root cause of food and environmental crises and associated local and global inequalities, to get a hearing, [24] Less capital-intensive solutions to food security challenges are marginalized from the discourse on sustainable agriculture and starved of investment [57]. These inequalities are apparent, for example, in food security discourse, which tends to focus on productivist approaches and digital technology as the solution. The digitalization of agriculture might further entrench this narrative and lead to the sidelining of alternative, low tech, or nontechnology-based responses to crises in the food system. This would make it more difficult for proposals to combat unequal access to food and the means of food production to gain a hearing, as pointed out by proponents of the food sovereignty concept. However, such technological fixes suit powerful actors from agribusiness, because they contribute to maintaining the status quo and to diverting attention away from the need to transform agriculture and challenge long-standing inequalities [24,71].

The inequalities in the ability to define problems and solutions are revealed in a recent analysis of high-level policy documents showing how international organizations such as the Food and Agriculture Organization or the World Bank envision future food systems. These organizations support the status quo, whereby industrial agriculture plays a dominant role in the food system, and prioritize the maximization of food output through the use of digital technology and "climate-smart" farming solutions. Organizational policy papers see digital technologies in agriculture as 'inevitable', since they are driven by technological innovation, and as 'needed' both to combat poverty and inequality and to cope with an increasingly unpredictable climate [8]. High-tech visions also attract much larger private and public investment than alternative agroecological approaches because they are seen as the most effective way to increase food security [8,57]. This is why some authors question whether the coexistence of the two systems, organic and agroecological on the one hand and conventional "Agriculture 4.0" on the other, is even possible. These authors argue that powerful actors will continue to dominate the trajectory of agricultural development, leading to the marginalization of alternative approaches given in [72]. Others argue that the two systems may be more complementary than is generally assumed by scientists and politicians, because farmers themselves will find ways to make them work together [24,73]. Discourse on "digital agroecology" explores avenues towards the use of digital technologies in order to advance core principles of agroecology, including equity, justice, participation, and co-construction of knowledge in agriculture [74]. As indicated by the findings of this review, small-scale and agroecological farmers are indeed inclined to adopt digital solutions that are open and affordable, such as those made available through the FarmHack network and other grassroots initiatives. In addition to affordability, these solutions are attractive to farmers because they are easy to apply and facilitate the sharing of knowledge. The democratic ownership of knowledge is explicitly welcome [74,75].

In addition to these grassroots initiatives, a number of companies are developing digital products tailored to the needs of agroecological, community-oriented or small-scale farmers $[1,17,76]$. In East Africa, the digital start-up WeFarm claims to have set up the largest farmer-to-farmer digital network, with more than a million users in Kenya and Uganda. WeFarm allows farmers to share questions, information, and advice through promotion of solutions that draw on local agricultural knowledge rather than marginalize it. The German-based company Rukola Soft [77] offers a planning tool for vegetable cultivation customized to the needs of community-supported agriculture [2]. Plantix is a free mobile app that promotes knowledge sharing and mutual learning among farmers [78]. It is used by small-scale farmers to diagnose and solve problems such as pest damage, plant disease, and nutrient deficiencies, and has links to La Via Campesina, the International Peasants' Movement, which campaigns for food sovereignty in the Global South [57].

\section{Discussion and Conclusions}

This review examined the social dimensions of digital agriculture based on published research findings. The aim was to identify the main patterns of inequality linked to the use 
of digital technologies in agriculture. Five interlinked patterns of inequality were identified, as summarized in Table 1.

First, there are inequalities in digital technology development, whereby corporate actors largely control and shape the development of infrastructure, products and services. Farmers are on the receiving end, struggling to cope with the lack of interoperability and constrained in their options by technical and legal lock-in effects.

Second, there are inequalities in distribution of benefits from the use of the technologies. Most digital technology is developed by industrial agri-tech firms and is designed to serve the needs of capital-intensive large-scale farms with high investment capacities. This deepens the rift between farmers who use digital technologies and those who are unable or unwilling to do so. It reinforces existing economic inequalities, since farmers who lack the capital to invest in digital technologies find themselves further disadvantaged. In addition, the uneven availability and accessibility of digital infrastructure (e.g., internet connectivity) disadvantages rural areas, reinforcing existing spatial patterns of economic inequality.

Third, there is uneven sovereignty over data, hardware, and digital infrastructure. Large technology providers benefit from using the data provided by farmers, while farmers themselves have limited access to and control over the data they have generated. They may even be prevented from repairing their own machines, under the terms of license agreements designed to increase farmers' dependency on licensed service providers.

Fourth, there are inequalities in 'digital literacy' among farmers, and between farmers and corporate providers of digital services. Many farmers lack the knowledge and skills required to process digital data, and find it difficult to find independent service providers or employees who are able to use and manage digital tools. Here, again, a spatial divide between farmers in urban and rural areas comes into play. Those farmers who lack the resources or the opportunity to develop digital skills become increasingly dependent on corporate providers not only for decision-making but also for the maintenance and repair of farm machinery.

Fifth, there are inequalities of power and influence over problem definition and problem solving. Powerful corporate actors shape the discourse, ensuring that the productivist vision of industrial agriculture remains predominant, while excluding alternative visions. This allows them to shape policies, whereby digitalization in the service of industrial agriculture is seen as the only way to achieve social and environmental goals. Alternative problem definitions, for example focusing on food sovereignty, and solutions, such as agroecology, are excluded from the discourse, widely ignored by policy makers, and starved of investment.

\subsection{Power Dimensions in Digital Agriculture}

The literature review also highlighted the existence of emancipatory initiatives dedicated to developing the potential of digital technologies to challenge existing inequalities. Coders and famers are collaborating to develop platforms for knowledge sharing and mutual learning alternatives and using them to advance alternative visions of agriculture. These initiatives underscore the political nature of digital agriculture; however, their reach is currently still quite limited. This is partly due to the fact that existing inequalities are structural, and expressions of "complex dimensions of corporate power, and concentration" [17]. The patterns of inequality identified in this review mainly relate to economic circumstances and the availabilities of financial and other resources. At the same time, they entail power inequalities in the sense that the powerful actors who possess these resources are able to shape not only the context but also the conduct of less powerful actors [79]. Actors from the agri-tech sector and technology providers promote proprietary products and services that, in part through the widespread use of lock-ins, primarily serve their own interests and preserve the status-quo of the agri-food system (context-shaping power). They thereby also limit the options available to farmers with regard to both the choice of tools to meet their needs and the use to which the data they generate is put. In addition, the influence of powerful actors sidelines efforts by other actors to promote an alternative 
vision of agricultural systems, and deprives them of the opportunity to demonstrate the viability of smaller-scale and less capital-intensive agriculture (conduct-shaping power).

Of course, these power relations in the digitalized agri-food system are not new; they are a continuation of what food regime theorists have called the 'corporate food regime' [33], and they are quite stable (for a discussion of continuities and shifts in the global food system, see [2]). This highlights the fact that the inequalities identified in this review are not caused by digital technologies but are new manifestations in the socio-technical sphere of existing social inequalities and power disparities. From such a perspective, digitalization in agriculture is not a 'revolution'. Digital technologies do not 'revolutionize' structural power relations; they mirror and reproduce them. Because of its tendency to leave underlying structures untouched, some authors even argue that the so called 'new' digital precision agriculture is still conventional agriculture, and better understood as part of a long-established production systems characterized by rationalization and control [69]. These authors identify continuities in the structural development and dynamics of agriculture and technology development [2]. They note that some features of the digital transformation of agriculture, for instance the use of the legal and digital lock-ins as part of a "top-down, closed platform model for the digitization of agriculture," were also features of previous innovations such as genetically modified organisms, which are widely known to exacerbate inequalities in the food system between smaller land-holders and large agri-businesses [67]. As political economy scholarship argues, addressing these patterns of inequality requires "structural shifts in food, environmental and trade policy at the national and global scale." [17].

Notwithstanding the structural character of these power relations and the need for macro-level changes to reduce the structural inequalities in digital agriculture, the opensource platforms and resistance movements identified in this review help to free farmers from technological lock-ins and reduce their dependency on proprietary technology systems. Of course, they cannot achieve this all at once, not least because farmers lack the capital to compete with proprietary systems. However, they go some way towards challenging existing power relations, and contribute to political change through their efforts to democratize data as a means of production. Digital infrastructure such as Rukola Soft facilitates trans-local food movements and the sharing of place-based knowledge for the benefit not only of farmers but also food sovereignty groups promoting an alternative vision of agriculture. By facilitating the emergence of alternative technology and knowledge regimes and bringing together the ideas of food sovereignty and data sovereignty [43], they contribute to the democratization of technology while challenging the power relations in which technology is embedded.

\subsection{Policy Challenges in Digital Agriculture}

The importance of national and supranational policies for the democratization of digital technology cannot be overstressed. Digital technology has the potential to contribute to socially and ecologically sustainable agriculture. In order to realize this potential, the social impacts and inequalities linked to digital agriculture need to become a key concern of policy makers, especially against the background of the United Nation's Sustainable Development Goals, which includes the goals of both reducing inequality and making agriculture more sustainable [80]. It is beyond the scope of this paper to analyze existing policy regulation and how it impacts the different patterns of inequality identified here. However, it is clear based on this review that the fragmented regulatory and legal framework governing the use of data and digital technologies in agriculture is in urgent need of reform. In the European Union, the existing legal framework is fragmentary and does not amount to a coherent policy framework. The existing assortment of instruments does not cover the complexity involved in the regulation of property rights and the ownership of digital assets. Among the principal existing policy instruments, the General Data Protection Regulation [81] only covers personal data, leaving businesses, and thus much of farm data, unaffected. However, it is not always clear whether farm data counts as 
personal or business data. This is the case, for example, when a farmer is sitting in a smart tractor or combine harvester that is recording everything she does. The Regulation on a Framework for the Free Flow of Non-Personal Data in the EU seeks to reduce the local storage and processing of non-personal data [82]. It encourages private license agreements and codes of conduct that allow the free flow of data and make it easy for customers to switch to other solutions and services. It is thus an important step forward towards a legal requirement for data portability and interoperability, and as such potentially contributes to the data sovereignty of farmers. Yet, it does not address the question of where data comes from and who 'owns' it. Finally, the European Union's Database Directive [83] tends to strengthen the position of data aggregators, providing neither ownership nor property rights for farmers in their capacity as 'raw data producers'. Thus, it is clear that the current instruments in the European Common Agricultural Policy "are poorly linked to the needs and challenges of digital economy" [56]. Of particular concern is that fact that there is no effective policy instrument in place in the European Union or in the United States that legally strengthens the sovereignty of farmers over their farm data $[46,56]$.

This review has explored the patterns of inequality associated with digital agriculture and identified some political initiatives from below that challenge these inequalities. The conclusions highlight the need for both researchers and policymakers to explore options and opportunities for the creation of a new digital agrarian law and to foster policy integration in order to regulate digital agriculture at different political scales. Moreover, in addition to adequate top-down policy regulation, attention should be given to the potential of bottom-up political movements to contribute to the reform of digital agriculture policy.

Still very little is known about the actual and potential contribution of alliances between open data initiatives and the food sovereignty movement to the democratization of data, the reduction of inequality, and the transformation of power relations. This kind of "emancipatory smart farming" [76], which was outside the scope of this review, is still in its infancy and merits close attention in further research.

Funding: This work was supported by the BMBF as part of the funding line 'Bioeconomy as Societal Change' FKZ 031B0750.

Institutional Review Board Statement: Not applicable.

Informed Consent Statement: Not applicable.

Data Availability Statement: The sample used in this study is available on request from the author.

Conflicts of Interest: The author declares no conflict of interest.

\section{References}

1. Birner, R.; Daum, T.; Pray, C. Who drives the digital revolution in agriculture? A review of supply-side trends, players and challenges. App. Econ. Persp. Policy 2021. [CrossRef]

2. Prause, L.; Hackfort, S.; Lindgren, M. Digitalization and the third food regime. Agric. Hum. Values 2020, 1-15. [CrossRef] [PubMed]

3. Wolfert, S.; Ge, L.; Verdouw, C.; Bogaardt, M.-J. Big Data in Smart Farming-A review. Agric. Sys. 2017, 153, 69-80. [CrossRef]

4. Khan, N.; Ray, R.L.; Kassem, H.S.; Hussain, S.; Zhang, S.; Khayyam, M.; Ihtisham, M.; Asongu, S.A. Potential Role of Technology Innovation in Transformation of Sustainable Food Systems: A Review. Agriculture 2021, 11, 984. [CrossRef]

5. Brennen, S.; Kreiss, D. Digitalization and Digitization-Culture Digitally. Available online: https://culturedigitally.org/2014/09/ digitalization-and-digitization (accessed on 17 October 2021).

6. Trendov, N.M.; Samuel, V.; Meng, Z. Digital Technologies in Agriculture and Rural Areas-Status Report: Status Report. Available online: https: / / www.fao.org/documents/card/en/c/ca4985en/ (accessed on 24 September 2021).

7. Newell, P.; Taylor, O. Contested landscapes: The global political economy of climate-smart agriculture. J. Peasant Stud. 2018, 45, 108-129. [CrossRef]

8. Lajoie-O'Malley, A.; Bronson, K.; van der Burg, S.; Klerkx, L. The future(s) of digital agriculture and sustainable food systems: An analysis of high-level policy documents. Ecosyst. Serv. 2020, 45, 101183. [CrossRef]

9. Mooney, P. Blocking the Chain: Industrial Food Chain Concentration, Big Data Platforms and Food Sovereignty. Available online: https://www.etcgroup.org/content/blocking-chain (accessed on 24 September 2021).

10. Carbonell, I.M. The ethics of big data in big agriculture. Internet Policy Rev. 2016, 5. [CrossRef] 
11. Bronson, K.; Knezevic, I. The Digital Divide and How It Matters for Canadian Food System Equity. CJC 2019, 44, PP63-PP68. [CrossRef]

12. Clapp, J.; Ruder, S.-L. Precision Technologies for Agriculture: Digital Farming, Gene-Edited Crops, and the Politics of Sustainability. Glob. Environ. Politics 2020, 20, 49-69. [CrossRef]

13. Regan, Á. 'Smart farming' in Ireland: A risk perception study with key governance actors. NJAS Wagening. J. Life Sci. 2019, 90-91, 100292. [CrossRef]

14. Rose, D.C.; Chilvers, J. Agriculture 4.0: Broadening Responsible Innovation in an Era of Smart Farming. Front. Sustain. Food Syst. 2018, 2, 571. [CrossRef]

15. Eastwood, C.; Klerkx, L.; Ayre, M.; Dela Rue, B. Managing Socio-Ethical Challenges in the Development of Smart Farming: From a Fragmented to a Comprehensive Approach for Responsible Research and Innovation. J. Agric. Environ. Ethics 2019, 32, 741-768. [CrossRef]

16. Klerkx, L.; Jakku, E.; Labarthe, P. A review of social science on digital agriculture, smart farming and agriculture 4.0: New contributions and a future research agenda. NJAS Wagening. J. Life Sci. 2019, 90-91, 100315. [CrossRef]

17. Rotz, S.; Duncan, E.; Small, M.; Botschner, J.; Dara, R.; Mosby, I.; Reed, M.; Fraser, E.D. The Politics of Digital Agricultural Technologies: A Preliminary Review. Sociol. Rural. 2019, 59, 203-229. [CrossRef]

18. Eastwood, C.; Klerkx, L.; Nettle, R. Dynamics and distribution of public and private research and extension roles for technological innovation and diffusion: Case studies of the implementation and adaptation of precision farming technologies. J. Rural. Stud. 2017, 49, 1-12. [CrossRef]

19. Bronson, K. Looking through a responsible innovation lens at uneven engagements with digital farming. NJAS Wagening. J. Life Sci. 2019, 90-91, 100294. [CrossRef]

20. Florey, C.; Hellin, J.; Balié, J. Digital agriculture and pathways out of poverty: The need for appropriate design, targeting, and scaling. EDM 2020, 31, 126-140. [CrossRef]

21. Ebrahimi, H.P.; Schillo, R.S.; Bronson, K. Systematic Stakeholder Inclusion in Digital Agriculture: A Framework and Application to Canada. Sustainability 2021, 13, 6879. [CrossRef]

22. Rijswijk, K.; Klerkx, L.; Bacco, M.; Bartolini, F.; Bulten, E.; Debruyne, L.; Dessein, J.; Scotti, I.; Brunori, G. Digital transformation of agriculture and rural areas: A socio-cyber-physical system framework to support responsibilisation. J. Rural. Stud. 2021, 85, 79-90. [CrossRef]

23. Rolandi, S.; Brunori, G.; Bacco, M.; Scotti, I. The Digitalization of Agriculture and Rural Areas: Towards a Taxonomy of the Impacts. Sustainability 2021, 13, 5172. [CrossRef]

24. Klerkx, L.; Rose, D. Dealing with the game-changing technologies of Agriculture 4.0: How do we manage diversity and responsibility in food system transition pathways? Glob. Food. Sec. 2020, 24, 100347. [CrossRef]

25. Perreault, T.A.; Bridge, G.; McCarthy, J. (Eds.) The Routledge Handbook of Political Ecology; Routledge International Handbooks; Routledge Taylor \& Francis Group: New York, NY, USA, 2015.

26. Gottschlich, D.; Hackfort, S.; Schmitt, T.; Winterfeld, U. (Eds.) Handbuch Politische Ökologie: Theorien, Konflikte, Begriffe, Methoden; Transcript Verlag: Bielefeld, Germany, in press.

27. Hackfort, S. Social-Ecological Inequalities: InterAmerican Wiki: Terms-Concepts-Critical Perspectives. Available online: https:// www.uni-bielefeld.de/einrichtungen/cias/publikationen/wiki/s/social-ecological-inequalities.xml (accessed on 23 September 2021).

28. Dietz, K. Sozial-ökologische Ungleichheiten: Zum Verhältnis von Gesellschaft, Natur und Demokratie in Lateinamerika. In Soziale Ungleichheiten in Lateinamerika: Neue Perspektiven auf Wirtschaft, Politik und Umwelt; Wehr, I., Burchardt, H.-J., Eds.; Nomos Verlagsgesellschaft mbH \& Co. KG: Baden-Baden, Germany, 2011; pp. 107-136.

29. Dietz, K. Researching Inequalities from a Socio-Ecological Perspective: Working Paper Series, desiguALdades.net Research Network on Interdependent Inequalities in Latin America. Available online: https:/ / www.desigualdades.net/Working_Papers/ Search-Working-Papers/working-paper-74-_researching-inequalities-from-a-socio-ecological-perspective_/index.html (accessed on 24 September 2021).

30. Allen, P.; Wilson, A.B. Agrifood Inequalities: Globalization and localization. Development 2008, 51, 534-540. [CrossRef]

31. Mares, T.M.; Alison, H.A. Mapping the Food Movement: Addressing Inequality and Neoliberalism. Environ. Soc. 2011, 2, 68-86. [CrossRef]

32. Motta, R. Social movements as agents of change: Fighting intersectional food inequalities, building food as webs of life. Sociol. Rev. 2021, 69, 603-625. [CrossRef]

33. McMichael, P. A food regime analysis of the 'world food crisis'. Agric. Hum. Values 2009, 26, 281-295. [CrossRef]

34. Friedman, H. From Colonialism to Green Capitalism: Social Movements and Emergence of Food Regimes. In New Directions in the Sociology of Global Development; Buttel, F.H., McMichael, P., Eds.; Research in Rural Sociology and Development v. 11; Elsevier: Amsterdam, The Netherlands, 2005; pp. 227-264.

35. Jayasuriya, S.K.; Shand, R.T. Technical change and labor absorption in Asian agriculture: Some emerging trends. World Dev. 1986, 14, 415-428. [CrossRef]

36. Patel, R. The Long Green Revolution. J. Peasant Stud. 2013, 40, 1-63. [CrossRef]

37. Pechlaner, G.; Otero, G. The Third Food Regime: Neoliberal Globalism and Agricultural Biotechnology in North America. Sociol. Rural. 2008, 48, 351-371. [CrossRef] 
38. Clapp, J.; Fuchs, D. (Eds.) Corporate Power in Global Agrifood Governance; Massachusetts Institute of Technology: Cambridge, MA, USA, 2009.

39. Snyder, H. Literature review as a research methodology: An overview and guidelines. J. Bus. Res. 2019, 104, 333-339. [CrossRef]

40. Wong, G.; Trish, G.; Gill, W.; Jeanette, B.; Ray, P. RAMESES publication standards: Meta-narrative reviews. BMC Med. 2013, 11, 20.

41. Baas, J.; Schotten, M.; Plume, A.; Côté, G.; Karimi, R. Scopus as a curated, high-quality bibliometric data source for academic research in quantitative science studies. Quant. Sci. Stud. 2020, 1, 377-386. [CrossRef]

42. Kuch, D.; Kearnes, M.; Gulson, K. The promise of precision: Datafication in medicine, agriculture and education. Policy Stud. 2020, 41, 527-546. [CrossRef]

43. Fraser, A. Land grab/data grab: Precision agriculture and its new horizons. J. Peasant Stud. 2019, 46, 893-912. [CrossRef]

44. Rotz, S.; Gravely, E.; Mosby, I.; Duncan, E.; Finnis, E.; Horgan, M.; LeBlanc, J.; Martin, R.; Neufeld, H.T.; Nixon, A.; et al. Automated pastures and the digital divide: How agricultural technologies are shaping labour and rural communities. J. Rural. Stud. 2019, 68, 112-122. [CrossRef]

45. Chiles, R.M.; Broad, G.; Gagnon, M.; Negowetti, N.; Glenna, L.; Griffin, M.A.M.; Tami-Barrera, L.; Baker, S.; Beck, K. Democratizing ownership and participation in the 4th Industrial Revolution: Challenges and opportunities in cellular agriculture. Agric. Hum. Values 2021, 38, 943-961. [CrossRef]

46. Atik, C.; Martens, B. Governing Agricultural Data and Competition in Data-driven Agricultural Services: A Farmer's Perspective: Competition Problems and Governance of Non-personal Agricultural Machine Data: Comparing Voluntary Initiatives in the US and EU. JRC Digital Economy Working Paper 2020-07. Available online: https://ideas.repec.org/p/ipt/decwpa/202007.html (accessed on 24 September 2021).

47. Jakku, E.; Taylor, B.; Fleming, A.; Mason, C.; Fielke, S.; Sounness, C.; Thorburn, P. "If they don't tell us what they do with it, why would we trust them?" Trust, transparency and benefit-sharing in Smart Farming. NJAS Wagening. J. Life Sci. 2019, 90-91, 100285. [CrossRef]

48. van der Burg, S.; Wiseman, L.; Krkeljas, J. Trust in farm data sharing: Reflections on the EU code of conduct for agricultural data sharing. Ethics Inf. Technol. 2020, 6, 275. [CrossRef]

49. Three River Farmers Alliance. Three River Farmers Alliance Fresh-Local-Delivered. Available online: https://www.threeriverfa. com/ (accessed on 17 October 2021).

50. Grower's Information Services Coop. AgHub-Grower's Information Services Coop. Available online: https://www.gisc.coop/ tools/aghub/ (accessed on 17 October 2021).

51. Thompson, N.M.; DeLay, N.D.; Mintert, J.R. Understanding the farm data lifecycle: Collection, use, and impact of farm data on U.S. commercial corn and soybean farms. Precis. Agric. 2021, 22, 1685-1710. [CrossRef]

52. Carolan, M. Automated agrifood futures: Robotics, labor and the distributive politics of digital agriculture. J. Peasant. Stud. 2020, 47, 184-207. [CrossRef]

53. Aulbur, W.; Robert, H.; Gilian, M.; Giovanni, S. Farming 4.0: How Precision Agriculture Might Save the World. Roland Berger GmbH. Munich. Available online: https://www.rolandberger.com/de/Insights/Publications/Landwirtschaft-4.0Digitalisierung-als-Chance.html (accessed on 17 October 2021).

54. Daum, T.; Villalba, R.; Anidi, O.; Mayienga, S.M.; Gupta, S.; Birner, R. Uber for tractors? Opportunities and challenges of digital tools for tractor hire in India and Nigeria. World Dev. 2021, 144, 105480. [CrossRef]

55. Higgins, V.; Bryant, M.; Howell, A.; Battersby, J. Ordering adoption: Materiality, knowledge and farmer engagement with precision agriculture technologies. J. Rural. Stud. 2017, 55, 193-202. [CrossRef]

56. Kosior, K. From Analogue to Digital Agriculture. Pol: ISEG Research Seminar, "Governance, Regulation and Economic Integration"; Lisbon School of Economics and Management, Conference Paper; University of Lisbon: Lisbon, Portugal, 2019.

57. Carolan, M. Digitization as politics: Smart farming through the lens of weak and strong data. J. Rural. Stud. 2020. [CrossRef]

58. U.S. PIRG. Right to Repair. Available online: https:/ / uspirg.org/feature/usp/right-repair (accessed on 17 October 2021).

59. Farm Hack. Farm Hack Network. Available online: https:/ / farmhack.org/tools (accessed on 17 October 2021).

60. Carolan, M. Publicising Food: Big Data, Precision Agriculture, and Co-Experimental Techniques of Addition. Sociol. Rural. 2017, 57, 135-154. [CrossRef]

61. Comi, M. The distributed farmer: Rethinking US Midwestern precision agriculture techniques. Environ. Sociol. 2020, 6, 403-415. [CrossRef]

62. Carolan, M. Urban Farming Is Going High Tech. J. Am. Plan. Assoc. 2020, 86, 47-59. [CrossRef]

63. Clark, B.; Glyn, J.; Helen, K.; James, T.; Yiying, C.; Wenjing, L.; Chunjiang, Z.; Jing, C.; Guijun, Y.; Liping, C.; et al. A proposed framework for accelerating technology trajectories in agriculture: A case study in China. Front. Agr. Sci. Eng. 2018, 5, 485-498. [CrossRef]

64. Rijswijk, K.; Klerkx, L.; Turner, J.A. Digitalisation in the New Zealand Agricultural Knowledge and Innovation System: Initial understandings and emerging organisational responses to digital agriculture. NJAS Wagening. J. Life Sci. 2019, 90-91, 100313. [CrossRef]

65. Ingram, J.; Maye, D. What Are the Implications of Digitalisation for Agricultural Knowledge? Front. Sustain. Food Syst. $2020,4,4$. [CrossRef]

66. Carolan, M. Acting like an algorithm: Digital farming platforms and the trajectories they (need not) lock-in. Agric. Hum. Values 2020, 99, 116. [CrossRef] 
67. Bronson, K. Digitization and Big Data in Food Security and Sustainability. In Encyclopedia of Food Security and Sustainability; Elsevier: Amsterdam, The Netherlands, 2019; pp. 582-587. [CrossRef]

68. Prause, L. Digital Agriculture and Labor: A Few Challenges for Social Sustainability. Sustainability 2021, 13, 5980. [CrossRef]

69. Miles, C. The combine will tell the truth: On precision agriculture and algorithmic rationality. Big Data Soc. 2019, 6, 205395171984944. [CrossRef]

70. Clapp, J. Explaining Growing Glyphosate Use: The Political Economy of Herbicide-Dependent Agriculture. Glob. Environ. Chang. 2021, 67, 102239. [CrossRef]

71. Rose, D.C.; Wheeler, R.; Winter, M.; Lobley, M.; Chivers, C.-A. Agriculture 4.0: Making it work for people, production, and the planet. Land Use Policy 2021, 100, 104933. [CrossRef]

72. Schnebelin, É.; Labarthe, P.; Touzard, J.-M. How digitalisation interacts with ecologisation? Perspectives from actors of the French Agricultural Innovation System. J. Rural. Stud. 2021, 86, 599-610. [CrossRef]

73. van Hulst, F.; Ellis, R.; Prager, K.; Msika, J. Using co-constructed mental models to understand stakeholder perspectives on agro-ecology. Int. J. Agric. Sustain. 2020, 18, 172-195. [CrossRef]

74. Wittman, H.; James, D.; Mehrabi, Z. Advancing food sovereignty through farmer-driven digital agroecology. IJANR 2020, 47, 235-248. [CrossRef]

75. EAKEN. Farm Hack: European Agroecology Knowledge Exchange (EAKEN) Network. Available online: https://www.fao.org/ agroecology/database/detail/en/c/1148876/ (accessed on 17 October 2021).

76. Fraser, A. 'You can't eat data'? Moving beyond the misconfigured innovations of smart farming. J. Rural. Stud. 2021. [CrossRef]

77. Rukola Soft UG. Philosophie-GEMÜSE Anbau Planer. Available online: https:/ /www.micro-farm-planner.com/philosophie/ (accessed on 17 October 2021).

78. PEAT GmbH. Plantix Best Agriculture App. Available online: https://plantix.net/en/ (accessed on 17 October 2021).

79. Hay, C. Political Analysis; Macmillan Education: Houndmills, UK, 2002. [CrossRef]

80. United Nations. THE 17 GOALS Sustainable Development. Available online: https://sdgs.un.org/goals (accessed on 17 October 2021).

81. European Union. General Data Protection Regulation (GDPR) Compliance Guidelines. Available online: https://gdpr.eu/ (accessed on 17 October 2021).

82. European Commission. Shaping Europe's Digital Future: Free Flow of Non-Personal Data. Available online: https:/ / digitalstrategy.ec.europa.eu/en/policies/non-personal-data (accessed on 17 October 2021).

83. European Parliament and Council of the Europen Union. Directive 96/9/EC on the Legal Protection of Databases. Available online: https:/ / eur-lex.europa.eu/LexUriServ/LexUriServ.do?uri=CELEX:31996L0009:EN:HTML (accessed on 17 October 2021). 